\title{
Protocol for Reports from Major Accidents and Disasters in the International Journal of Disaster Medicine*
}

\author{
Sten Lennquist ${ }^{1}$
}

\begin{abstract}
The aim of this protocol is to achieve a prospective, standardized methodology for reporting results and experiences from major accidents and disasters so that the data can be used for analysis, to compare results, to exchange experiences and for international collaboration in methodological development. Using this form, the authors of the reports retain full credit for the data and the publication of them. At the same time, the data will be available in the journal and on the Internet (www.europeantrauma.net), thus providing the abovementioned possibilities for scientific analysis and development.
\end{abstract}

\section{Key Words \\ Major incidents - Mass-casualty incidents . \\ Disaster protocol - Quality assurance}

Eur J Trauma Emerg Surg 2008;34:486-92

DOI $10.1007 / \mathrm{s} 00068-008-8806-1$

\section{Use of the Protocol}

The protocol will be permanently available on the journal website (www.europeantrauma.net) and can also be requested at any time by e-mail, fax or regular mail from the editorial office (ejt@trauma.uni-frankfurt.de). It will be distributed to international and national societies and disaster medicine organizations, national and international centers, and persons known to have key positions in education about and the development of disaster medicine. We call for national representatives who are willing to take on the distribution of the protocol within their countries, and it is our hope that (over time) it will become available to the extent that it can conse- quently be used prospectively. However, at least in the beginning, we also want to leave the door open for retrospective use of the protocol, and it is our aim to send it to disaster sites in an attempt to obtain a report produced according to the protocol for publication. Readers will be informed whether the protocol has been used prospectively or retrospectively. The protocol can be used either by staff from the locally involved organizations or by external observers, but then it has to be in agreement and/or in collaboration with the local organizations, which should be clearly confirmed in cases where an external observer submits a report.

\section{Guidelines for the User}

The report should be written with the headings below, using the relevant boxes. Commentaries for each box are optional and should be a maximum of five lines of manuscript for each commentary.

\section{Short Summary of the Scenario}

Location, time, what happened, type and number of injuries (maximum of ten lines).

\section{Description of Hazard(s) Causing the Accident} Short description of the hazard(s) resulting in the accident, for example (maximum of ten lines):

- Airport, railway, ship - type and intensity of traffic

- Mass gatherings - type of activity and volume

- Hazardous material - type(s) of agents in production/transport

- Nuclear plant - type, surroundings, population

- Terrorist activity - anticipated scenarios

- Natural disasters - type, incidents and calculated risk, size and density of population

'Department of Surgery (Professor Emeritus), University Hospital, Linköping, Sweden. 


\section{Description of the Accident (Maximum of Ten Lines)}

- Time: day, hour, office or nonoffice hours (weekend, holiday)

- Location: if possible indicate on a schematic map with given distances to available resources (see Table 4)

- Climate: temperature, wind, rain/snow, daylight

- Short description of the accident and its immediate effects: extent of material destruction

- The time when the first alarm reached the alarm center (or other unit, if first alerted)
Prehospital Resources Available and Alerted Use Table 1 accompanied by a (schematic and simple) map of the area that indicates distances from the scene.

Comment briefly on the planned organization for the command of and coordination between different units.

\section{Hospital Resources Available and Alerted}

\section{Use Table 2.}

Comment briefly on the character of each hospital, and whether it was included in the disaster preparedness and planning process at the time of the accident.

Table 1. Prehospital resources available/alerted.

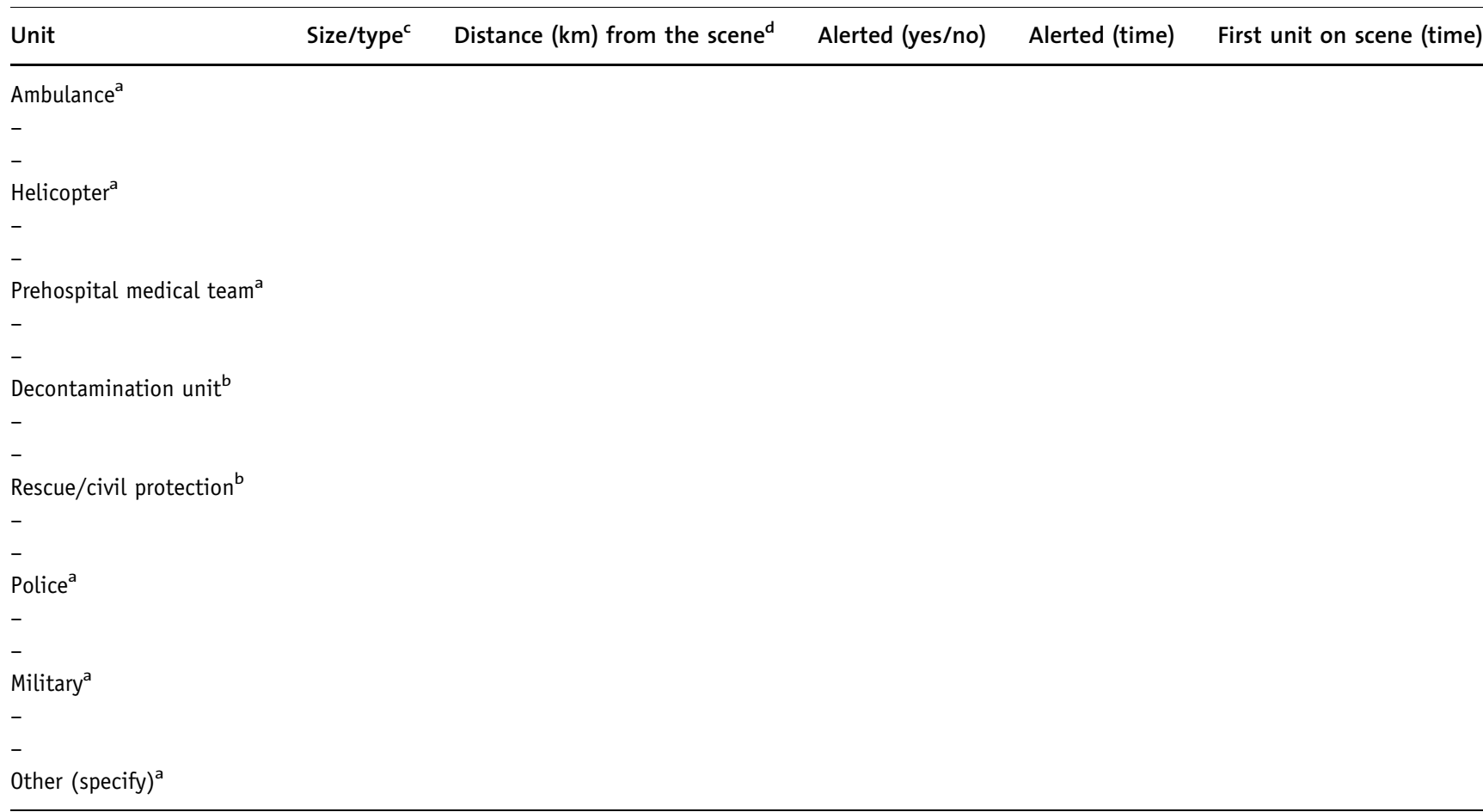

${ }^{\mathrm{a}} \mathrm{Also}$ indicate command and coordinator center, if available

bIf relevant for this scenario

${ }^{c}$ For ambulances, helicopters and prehospital teams: number and capacity of unit, level of staff (doctor/nurse/paramedic). For rescue/civil protection: voluntary/permanent, number of available staff, special resources (tents, bandwagons). For police and military: number of available staff, special resources. (Available staff $=$ staff usually available at the time when the accident occurred.)

${ }^{\mathrm{d}}$ If possible, include a figure with a schematic map

Table 2. Hospital resources available/alerted (include all involved hospitals in the same table).

\begin{tabular}{|c|c|c|c|c|c|c|c|c|}
\hline $\begin{array}{l}\text { Name of } \\
\text { hospital }\end{array}$ & $\begin{array}{l}\text { Distance from } \\
\text { the scene }\end{array}$ & $\begin{array}{l}\text { Total } \\
\text { beds }\end{array}$ & $\begin{array}{l}\text { ICU } \\
\text { beds }\end{array}$ & Ventilators & $\begin{array}{l}\text { Operating } \\
\text { theaters }\end{array}$ & $\begin{array}{l}\text { Trauma } \\
\text { unit (yes/no) }\end{array}$ & $\begin{array}{l}\text { Burn unit } \\
\text { (yes/no) }\end{array}$ & $\begin{array}{l}\text { Decontamination } \\
\text { (yes/no) }\end{array}$ \\
\hline
\end{tabular}




\section{Utilization of Transport Resources}

Use Table 3 .

Comment briefly on whether the capacity was accurately utilized (over- or underalert).

\section{Hospital Alert Plan and Response}

\section{Use Table 4.}

Comment briefly on whether the hospital resources were accurately utilized (over- or underalert).

\section{Coordination and Command}

\section{Use Table 5.}

Comment briefly as to whether the organization of the command and coordination was considered accurate.

\section{Hospital Damage}

Use Table 6.

Comment briefly on how long the dysfunction(s) lasted, and whether reserve systems were prepared and did indeed function.

\section{Communication System}

Use Table 7.

Comment briefly on whether the access to communication systems was sufficient, whether they were well coordinated, and whether the staff were sufficiently trained to use them effectively.

\section{Computer Technology and Back-Up Systems}

\section{Use Table 8.}

Comment briefly on whether the experiences indicated a need for extended back-up (reserve) systems, and if so, which one(s).

\section{Total Number and Type of Injuries}

Use Table 9.

Comment briefly on which figures are exact and which are estimated.

\section{Severity of Injuries}

Always use Table 10, and also Table 11 whenever data are available. (ISS: injury severity score).

Table 3. Utilization of transport resources.

\begin{tabular}{lllll}
\hline Unit & $\begin{array}{l}\text { Number } \\
\text { alerted }\end{array}$ & $\begin{array}{l}\text { Number used } \\
\text { in action }\end{array}$ & $\begin{array}{l}\text { Number of } \\
\text { transported patients }\end{array}$ & $\begin{array}{l}\text { First unit departs } \\
\text { with patient }\end{array}$ \\
\hline
\end{tabular}

Ambulance

Regular $^{a}$

Special $^{\mathrm{a}}$

Military ${ }^{a}$

Helicopter $^{\mathrm{a}}$

1-2 Stretchers

$>2$ Stretchers

Bandwagon

Bus

Train

Ship

Aircraft

Truck

Taxi

Private car

Other (specify)

${ }^{a}$ Capacity can also be specified

Table 4. Hospital alert plan and response (include all hospitals involved in the same table).

\begin{tabular}{lllll}
\hline $\begin{array}{l}\text { Name of } \\
\text { hospital }\end{array}$ & $\begin{array}{l}\text { Distance } \\
\text { to scene }\end{array}$ & $\begin{array}{l}\text { Hospital } \\
\text { alerted (yes/no) }\end{array}$ & $\begin{array}{l}\text { Disaster plan } \\
\text { available (yes/no) }\end{array}$ & $\begin{array}{l}\text { Disaster plan } \\
\text { activated (yes/no) }\end{array}$ \\
\hline
\end{tabular}


Table 5. Coordination and command.

\begin{tabular}{ll}
\hline Unit & Organization for coordination and command \\
\cline { 2 - 2 } & Was prepared (yes/no) \\
\hline Ambulance & \\
Helicopters & \\
Prehospital medical teams \\
Hospitals \\
Rescue/civil protection \\
Police \\
Military
\end{tabular}

ascoring:

$1=$ Never alerted or staffed

$2=$ Alerted but did not function

3 = Did function, but needs major improvement

$4=$ Did function, needs minor improvement

$5=$ Did function well

Table 6. Hospital damage (communication see Table 7, computer technology see Table 8) (include all hospitals involved in the same table). Name of hospital Material damage causing dysfunction (0-100\%)

\begin{tabular}{|c|c|c|c|c|c|}
\hline $\begin{array}{l}\text { Emergency } \\
\text { department }\end{array}$ & Surgery & $\begin{array}{l}\text { Intensive } \\
\text { care }\end{array}$ & Wards & $\begin{array}{l}\text { Dysfunction of } \\
\text { electrical supply (0-100\%) }\end{array}$ & $\begin{array}{l}\text { Dysfunction of water } \\
\text { supply (0-100\%) }\end{array}$ \\
\hline
\end{tabular}

Table 7. Communication systems.

\begin{tabular}{|c|c|c|}
\hline Unit & System and function (s & \\
\hline & External telephone net & Internal telephone net \\
\hline
\end{tabular}

Ambulance

Helicopter

Prehospital teams

Hospitals

Rescue/civil protection

Police

Military

ascoring:

$0=$ Was not used

$1=$ Did not function

$2=$ Did function up to a point (unreliable)

$3=$ Did function well 
Table 8. Computer technology and back-up systems.

\begin{tabular}{|c|c|c|c|}
\hline Unit & $\begin{array}{l}\text { Computer system } \\
\text { Used (yes/no); function (score } 1-3)^{a}\end{array}$ & $\begin{array}{l}\text { Computer back-up system } \\
\text { Used (yes/no); function (score 1-3) }\end{array}$ & $\begin{array}{l}\text { "Manual" back-up system } \\
\text { Used (yes/no); function (score 1-3) }\end{array}$ \\
\hline \multicolumn{4}{|c|}{ Ambulance } \\
\hline \multicolumn{4}{|l|}{ - } \\
\hline \multicolumn{4}{|l|}{-} \\
\hline \multicolumn{4}{|c|}{ Hospital } \\
\hline \multicolumn{4}{|l|}{-} \\
\hline \multicolumn{4}{|l|}{-} \\
\hline \multicolumn{4}{|c|}{ Rescue/civil protection } \\
\hline \multicolumn{4}{|l|}{ Police } \\
\hline Military & & & \\
\hline
\end{tabular}

ascoring:

$1=$ Did not work

$2=$ Worked up to a point (unreliable)

$3=$ Worked well

Table 9. Total number and type of injuries.

\begin{tabular}{l}
\hline Type \\
Mechanical violence \\
Fire \\
Inhalation \\
Corrosive agents \\
Irradiation \\
Cold \\
Drowning \\
Biological contamination (specify) \\
Other (specify) \\
Total
\end{tabular}

Comment briefly on which figures are exact and which are estimated.

\section{Why ISS?}

There are probably as many opinions on which scoring system should be used in these situations as there are people working in disaster medicine, and most of these opinions are probably justified from some points of view. The reasons for suggesting ISS in this protocol are that:

- It is based on data that can and should be collected after the initial phase of the accident. Realistically, the middle of a major accident/disaster, with its highly pressed atmosphere, is not the best place to collect data like these, even though it would theoretically provide a useful aid for triage and reporting. In addition, complete data are not available until after the final diagnosis.
Table 10. Severity of injuries according to treatment.

\begin{tabular}{l} 
Type \\
\hline Less severe injuries not examined or treated by medical \\
professionals ${ }^{\mathrm{a}, \mathrm{b}}$ \\
Less to moderately severe injuries examined and/or \\
treated by medical professionals \\
Outside hospital \\
In hospital $^{\mathrm{a}}$ \\
Injuries requiring in-hospital care/observation \\
In a regular ward \\
In intensive care \\
Requiring a ventilator \\
Injuries requiring surgery \\
Immediately \\
Within $6 \mathrm{~h}$ \\
Delayed
\end{tabular}

${ }^{a}$ Medical professionals defined as ambulance staff, paramedics, nurses and doctors

${ }^{b}$ In extensive scenarios, it may be necessary to estimate the figures

- It should be possible to obtain the data required for the ISS in any organization or hospital, at least for severely injured patients.

- There is extensive experience of the use of the ISS system for comparing outcome with score (assuming that the age of the patient is factored in), and there are data that indicate what the anticipated outcome should be for different scores and age levels. These data are from "normal" trauma care, and the same results cannot be expected in major accidents and disasters, but collecting them in such situations instead of starting new scoring systems that are 
Table 11. Severity of injuries according to injury severity score (ISS).

\begin{tabular}{l} 
ISS range \\
\hline $1-15$ \\
$16-20$ \\
$21-30$ \\
$31-40$ \\
$41-50$ \\
$51-60$ \\
$61-75$
\end{tabular}

Used only for injuries caused by mechanical violence and when data from the final diagnosis are available

especially for disasters can provide the basis for comparing results related to the severity of the scenario. Hopefully, in the future there will be a similar basis for scoring injuries caused by NBC (nuclear/biological/chemical) agents, but until then we will have to use a simpler scoring system in those situations (Table 8).

\section{Hospital Load}

Use Table 12.

Comment briefly on whether any hospital was "overloaded," i.e., patients could not be optimally treated because of congestion and/or a lack of personnel and material resources.

\section{Psychological Reactions}

\section{Use Table 13.}

Comment briefly on the strategy and plan for dealing with psychological reactions in the area.

\section{Outcome}

Use Table 14.

For trauma patients, the ISS should (if possible) always be used for dead and disabled individuals.

Table 12. Hospital load (include all hospitals involved in the same table).

\begin{tabular}{lllllll}
\hline Name of hospital & Number of hospitalized patients & & Surgery & \\
\cline { 2 - 3 } \cline { 4 - 6 } & $\begin{array}{l}\text { Number of patients in } \\
\text { ambulatory care (outpatients) }\end{array}$ & $\begin{array}{l}\text { In regular } \\
\text { ward }\end{array}$ & In ICU & $\begin{array}{l}\text { Requiring } \\
\text { ventilator }\end{array}$ & $\begin{array}{l}\text { Number of operations } \\
\text { under general anesthesia }\end{array}$ & $\begin{array}{l}\text { Number of operations } \\
\text { under local anesthesia }\end{array}$ \\
\hline
\end{tabular}

Table 13. Psychological reactions and management.

\begin{tabular}{l} 
Treatment \\
\cline { 2 - 3 }
\end{tabular}

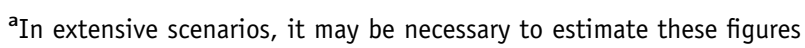

Table 14. Outcome with regard to mortality and persistent disability.

$\begin{array}{lllll}\text { Patient no. ISS (or short description) } & \text { Age } \quad \text { Dead on scene } & \begin{array}{l}\text { Dead during } \\ \text { transport }\end{array} & \text { Dead in hospital } & \begin{array}{l}\text { Surviving but } \\ \text { permanently disabled }\end{array}\end{array}$

\footnotetext{
${ }^{a}$ If access to data makes it possible, use ISS. If not, use a short description of the injury; for multiple injuries (which are the most common in these situations, based on experience), underline the most severe. For limited numbers of patients, both can be used

${ }^{b}$ Significant disability as evaluated at the time of the report (loss of limb or part of it, neurological dysfunction, severe respiratory or gastrointestinal dysfunction)
} 
Table 15. Estimated number of people affected but not injured.

\begin{tabular}{llll}
\hline Type of effect & Total number & Taken care of by relief organizations (\%) \\
\cline { 3 - 3 } & & Not at all & \\
\hline Loss of home & & Satisfactory \\
Lack of food \\
Lack of water \\
Lack of heating \\
Lack of electricity \\
Secondary infections \\
Refugees \\
Prisoners (armed conflict, terror)
\end{tabular}

Table 16. Post-accident evaluation of the quality of preparedness.

\begin{tabular}{|c|c|c|c|c|c|c|c|}
\hline \multirow[t]{2}{*}{ Unit/organization } & \multicolumn{7}{|c|}{ Accuracy of disaster plan } \\
\hline & $\begin{array}{l}\text { Disaster plan } \\
\text { existed (yes/no) }\end{array}$ & $\begin{array}{l}\text { Plan activated } \\
\text { (yes/no) }\end{array}$ & $\begin{array}{l}\text { Did not exist, } \\
\text { or did not } \\
\text { function at all }\end{array}$ & $\begin{array}{l}\text { Did function } \\
\text { in limited parts }\end{array}$ & $\begin{array}{l}\text { Did function } \\
\text { in most parts, } \\
\text { but needs } \\
\text { minimal revision }\end{array}$ & $\begin{array}{l}\text { Did function, } \\
\text { requires } \\
\text { major revision }\end{array}$ & $\begin{array}{l}\text { Functioned fully } \\
\text { and accurately }\end{array}$ \\
\hline
\end{tabular}

Table 17. Post-accident evaluation of training.

\begin{tabular}{lllll}
\hline $\begin{array}{l}\text { Unit/ } \\
\text { organization }\end{array}$ & $\begin{array}{l}\text { Had any training } \\
\text { or exercise } \\
\text { been done? }\end{array}$ & Extent and accuracy of training & \\
\cline { 3 - 5 } & Useless & $\begin{array}{l}\text { Highly } \\
\text { insufficient }\end{array}$ & $\begin{array}{l}\text { Partly insufficient, } \\
\text { additional training } \\
\text { needed }\end{array}$ & $\begin{array}{l}\text { Extent of training } \\
\text { sufficient, } \\
\text { but not accurate } \\
\text { for the purpose } \\
\text { required }\end{array}$ \\
\end{tabular}

\section{Estimated Number of People Affected but not Injured}

Use Table 15.

Comment briefly on which relief organizations or others were involved in the support of affected groups of people (for psychological reactions and their management see Table 13).

\section{Post-Accident Evaluation}

Use Tables 16 and 17. Add a conclusion, with a pointby-point list of both the positive and the negative experiences (half to a full page of manuscript).

Submit your report as soon as possible after the accident. It will be published with high priority either in the journal or on the website, referred to and promptly commented upon in the journal. Consider that every report increases the chances of improving preparedness and saving life and health, and we trust that you regard that worth the effort.

We welcome your reports to the European Journal of Trauma and Emergency Surgery (manuscript submission at http://mc.manuscriptcentral.com/ejt)

\footnotetext{
Address for Correspondence

Prof. Sten Lennquist

Ängslyckestigen 4

61432 Söderköping

Sweden

Tel: $(+46 / 121)$ 142-49

Fax: -49

e-mail: lennquist@telia.com
} 